\title{
To the Editors:
}

\section{Quadriparesis after a wasp sting}

\author{
A Narayan, R Mohan, M A Gowda
}

Ceylon Medical Journal 2016; 61: 45 DOI: http://doi.org/10.4038/cmj.v61i1.8265

A 30-year-old male patient, employed as a security guard, was brought to the hospital with weakness of all four limbs after being stung by a wasp on the back of the neck the previous evening. He had mild swelling and pain at the site, which resolved on the same day. The patient had received an intramuscular injection of tetanus toxoid that night. The next morning the patient awoke from sleep and realised that he was unable to rise from bed, due to weakness in the upper and lower limbs. He was otherwise healthy and had no history of recent medications or abuse of drugs or alcohol.

On admission he was conscious, co-operative and oriented. He had flaccid quadriparesis with weakness of proximal and distal groups of muscles and power of grade 2/5. There was weakness of neck muscles with head lag. Deep tendon reflexes of the upper limbs were sluggish. Lower limb reflexes were normal with bilateral flexor plantar response. There was no sensory loss and the cranial nerves were normal. Examination of other systems was normal. Full blood count, liver, renal and thyroid function tests were normal. Human immunodeficiency virus (HIV) and hepatic viral markers were negative. Serum sodium, chloride, calcium, phosphate, magnesium, random sugar, creatinine and phosphokinase levels were within normal range. Arterial blood gas analysis, chest radiograph and ultrasound of abdomen and pelvis were normal.
Since serum potassium level was very low, $1.3 \mathrm{mEq} / \mathrm{dl}$ (normal range 3.5-5 mEq/ dl) and ECG showed prominent $\mathrm{U}$ waves, a diagnosis of hypokalemic paralysis was made. Potassium was replenished and muscle power returned to normal in all four limbs after 48 hours, and ECG changes resolved. Nerve conduction studies were normal in all limbs. The patient recovered completely and remained asymptomatic at follow up after one year.

Quadriparesis has been reported after wasp stings due to acute inflammatory demyelinating polyneuropathy, encephalomyeloradiculopathy and hypokalemia associated with type I renal tubular acidosis [1-3]. It appears that the wasp venom has the potential to induce muscular paresis by inducing hypokalemia only as shown in this case.

\section{References}

1. Agarwal V, DCruz S, Sachdev A, et al. Quadriparesis following wasp sting: An unusual reaction. Indian J Med Sci 2005; 59: 117-9.

2. Likittanasombut P, Witoonpanich R, Viranuvatti K. Encephalomyeloradiculopathy associated with wasp sting. J Neurol Neurosurg Psych 2003; 74: 134-5.

3. D'Cruz S, Chauhan S, Singh R, et al. Wasp sting associated with type 1 renal tubular acidosis. Nephrol Dial Transplant 2008; 23: 1754-5.

Department of General Medicine, M S Ramaiah Medical College, Bengaluru, India.

Correspondence: RM, e-mail: <mohan.ranjit21@gmail.com>. Received 7 September and revised version accepted 23 November 2015. 